\title{
Kajian Sistem Radiografi Digital sebagai Pengganti Sistem Computed Radiography yang Mahal
}

\author{
Susilo $^{1 *}$, Sunarno ${ }^{1}$, I Ketut Swakarma ${ }^{2}$, Rudi Setiawan ${ }^{3}$, Edy Wibowo ${ }^{4}$ \\ 1 Jurusan Fisika FMIPA UNNES, Kampus Unnes Sekaran - Gunungpati Semarang \\ ${ }^{2}$ Jurusan Teknik Elektro FT Universitas Dian Nuswantoro Semarang, Jl. Nakula I No. 5-11 Semarang. \\ 3 Jurusan Fisika FSM UNDIP, Kampus Undip Tembalang Semarang. \\ ${ }^{4}$ Jurusan Fisika FPS ITB, Kampus ITB Bandung \\ *Alamat email: susilosumarto@yahoo.com
}

\begin{abstract}
Abstrak - Sisitem radiografi diagnostic yang ada pada bagian radiologi Rumah Sakit Daerah (RSD) atau Puskesmas di Indonesia umumnya masih menggunakan system Radiografi Konvensional (RK) dengan film radiograf sebagai media penangkap citra. Berbeda dengan system Computed Radiography (CR) tanpa film (filmless) yang sudah ada di RS tipe A atau RS maju di kota-kota besar. Dalam studi sebelumnya telah dilakukan pencitraan system radiografi digital diagnostic berbasis $X$-Ray Intensifying Screen, diperoleh file radiograf digital dengan resolusi rendah, sehingga kalau dibesarkan citra radiograf menjadi pecah. Pada studi kali ini telah dikaji kemungkinan penggunaan kamera digital jenis single lens reflex pada ruang kedap cahaya. Hasil eksperimen diperoleh hasil file radiograf digital dengan resoluasi lebih tinggi dibanding sebelumnya. Kajian ini bisa dikembangkan menjadi system radiografi digital dengan memodifikasi unit penangkat gambar pada sistem RK, sehingga sistem ini bisa menjembatani antara pembacaan radiograf analog menggunakan film menjadi file radiograf digital, sekaligus sebagai pengganti sistem $C R$ yang relative mahal.
\end{abstract}

Kata kunci: radiografi digital, file radiograf, resolusi

Abstract - Diagnostic radiography systems that exist in the radiology division of Regional Hospital (RH) or health centers in Indonesia are still using Conventional Radiography system with film as a medium of radiograph image catcher. This system is different with the filmless Computed Radiography system (CR) that already exist in the hospital of type A or advanced hospitals in major cities. In the previous studies we conducted the diagnostic digital radiography imaging system based on $X$ Ray Intensifying Screen. It was obtained the digital radiographs file with low resolution level so that if the radiographs file are magnified resulting the blurred image. In this study we examined the possibility of using the type of digital single lens reflex camera in a light-tight chamber. The experimental results that are obtained shows the digital radiographs file with higher resolution than ever before. This study could be developed into a digital radiography system by modifying the video capture unit on Conventional Radiography system so that the system is able to connected the gap between the reader of analog radiographs film into the digital radiographs file, as well as a replacement of CR systems that are relatively expensive.

Key words: digital radiography, radiographs file, resolution

\section{PENDAHULUAN}

Teknologi radiografi diagnostik untuk kepentingan medis yang digunakan pada bagian radiologi di rumah sakit (RS) tipe A atau RS kota-kota besar sudah bergeser dari teknologi radiografi konvensional berbasis film menjadi teknologi radiografi digital tanpa film (filmless), yaitu menggunakan sistem Computed Radiography (CR). Untuk pengadaan sistem CR tentu saja membutuhkan dana yang relatif besar, apalagi untuk perawatan dan penyediaan sumber daya yang tersedia. Bagaimana dengan situasi bagian radiologi di RS Daerah atau Puskesmas di Indonesia? Umumnya masih menggunakan sistem Radiografi Konvensioal (RK), seperti ditunjukkan secara skematik pada Gambar 1. Keadaan seperti ini terbentur masalah keterbatasan dana dan kesiapan sumber daya manusianya. Tapi pada perkembangannya sistem radiografi tersebut, prinsip radiografi sinar- $\mathrm{X}$ sendiri relatif sama seperti pada saat sinar-X ditemukan, yaitu adanya $x$-ray generator, .kaset film, kamar gelap dan media penangkap gambar atau radiograf film [1].

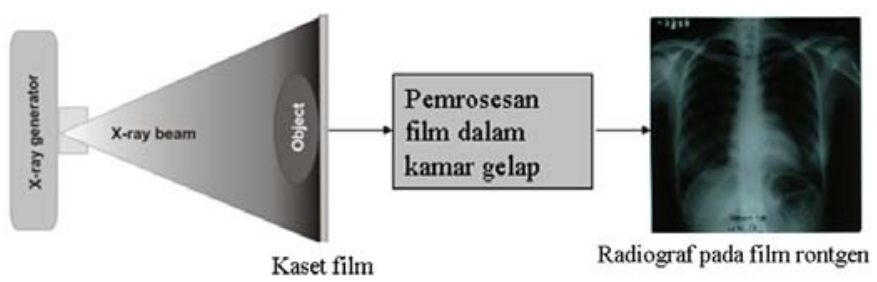

Gambar 1. Sistem Radiografi Konvensional

Beberapa cara aplikasi radiografi tanpa film telah dilakukan, antara lain dengan teknik digitisasi film radiograf atas prinsip densitas optik.

Modifikasi sistem RK menjadi sistem Radiografi Digital (RD) dilakukan dengan menambah unit tabung 
kedap cahaya dibelakang intensifying screen sehingga bayangan obyek bisa ditangkap oleh kamera CCD, kemudian diteruskan ke unit frame grabber atau penangkap gambar VC (video capturer). Data digital yang diperoleh diteruskan ke komputer $P C$ dengan software pengolah citra untuk kemudian citra ditampilkan pada layar monitor PC, seperti ditunjukkan pada Gambar 2 [2].

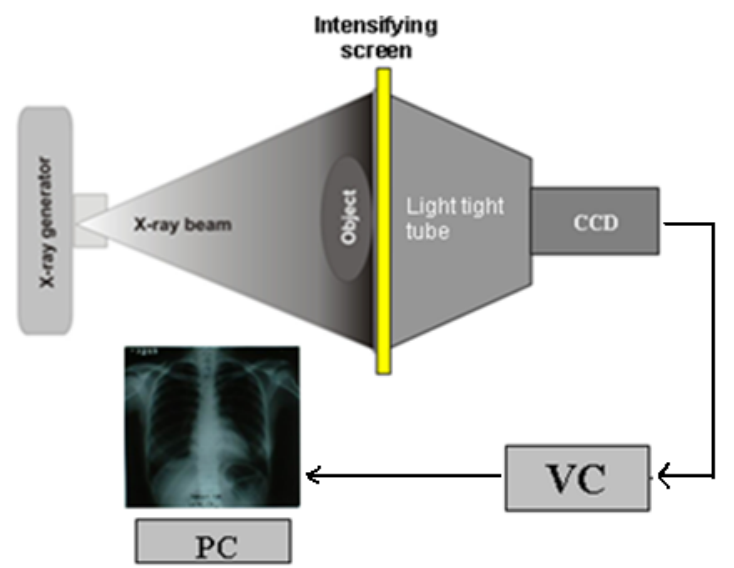

Gambar 2. Sistem RD menggunakan kamera CCD

Pada makalah ini didiskusikan tentang hasil kajian pencitraan radiografi digital sinar-x berbasis intensifying screen yang telah didigitisasi menggunakan kamera digital. Keuntungan yang diperoleh melalui pemanfaatan intesifyig screen dan kamera tersebut adalah bahwa perangkat tersebut relatif banyak tersedia di pasar domestik diikuti dengan kemudahan perolehan sukucadang.

\section{LANDASAN TEORI (JIKA DIPERLUKAN)}

\section{A. Intensitas Sinar- $X$}

Citra radiograf yang dihasilkan oleh sistem radiografi pada dasarnya adalah pemetaan dari berkas sinar-X yang diteruskan $I$, berkas mula-mula yang datang $I_{o}$, tebal obyek $\mathrm{x}$ dan kepadatan obyek (tulang) $\lambda$, dimana secara matematis dinyatakan sebagai persamaan (1):

$$
I=I o \exp (-\lambda x)
$$

Intensifying screen dapat difungsikan untuk mengubah sinar-X yang tidak tampak menjadi sinar tampak, sehingga gambar bisa direkam menggunakan kamera digital.

\section{B. Sistem Computed Radiography}

Teknologi CR ini menggunakan detektor photostimulable yang menggantikan kaset screen film (SF) pada system RK. Plat storage-phosphor dimasukkan di dalam kaset dengan dimensi standard untuk radiografi hitam-putih khas tanpa mengubah generator sinar-X, dinding Bucky dan tabung sinar- $\mathrm{x}$ atau sistem meja paparan. Teknologi CR memberikan keleluasan radiografer untuk memperoleh citra radiografi hitam-putih lebih baik dibanding unit SF pada sistem RK. Perbedaan dengan sistem RK adalah bagaimana citra laten diciptakan dan bagaimana pengolahan citra ini dikerjakan. Siklus pencitraan CR dasar mempunyai tiga langkah (lihat Gambar 3): (i) pemaparan, (ii) readout, dan (iii) menghapus [3]. Keluaran dari CR ini adalah citra radiograf yang bisa dinyatakan dalam bentuk tingkat keabuan pixel berupa angka-angka secara kuantitatif [4].

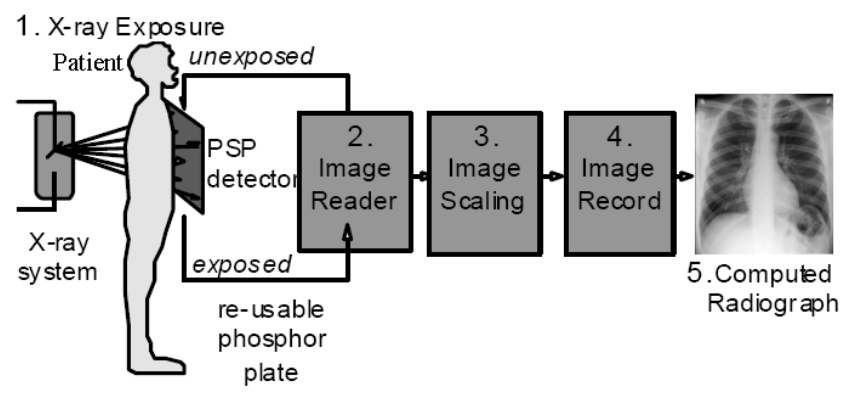

Gambar 3. Langkah siklus pencitraan sistem CR [5]

Pengadaan sistem CR untuk saat ini masih merupakan barang langka terutama untuk unit pelayanan radiologi RS Daerah atau Puskesmas di Indonesia, relatif belum terjangkau oleh keuangan yang dikelola oleh APBD Daerah, belum lagi sistem perawatan dan ketersediaan sumber daya manusia. Sebagai gambaran RS Semarang dan Yogyakarta yang menggunakan sistem pelayanan radiodiagnostik menggunakan sistem CR adalah: RSUP Dr. Kariadi, RS Elisabeth, RS Telogrejo (Semarang), RSUP Dr. Sardjito, RS Bethesda.

Untuk itu semua kiranya perlu dikaji sistem RD berbasis kamera digital, sehingga bisa menjembatani antara sistem RD tanpa film dan RK yang analog ysng masih digunakan di RS Daerah atau Puskesmas sampai saat ini.

\section{METODE PENELITIAN/EKSPERIMEN}

\section{A. Bahan dan Peralatan}

Penelitian dilakukan lab Fisika Medik - Jurusan Fisika FMIPA UNNES Semarang. Peralatan utama yang digunaan adalah: unit Mobile X-ray (biasa digunakan pada rumahsakit Daerah atau Puskesmas), dengan merk/type Mednif/SF-100BY [6]. Komponen penting dari unit Mobile $X$-ray tersebut antar lain: fasilitas tabung sinar-X, generator tegangan tinggi beserta control table, yang biasa disebut dengan sistem radiografi konvensional (RK), sketsel dari timbal sebagai unit protesi radiasi yang dilengkapi dengan kaca timbal untuk mengintip kesiapan pasien yang akan dipotret. Untuk keamanan operator dan pasien mesin radiografi diagnostik ditempatkan pada ruang kedap cahaya terbalut timbal $1,5 \mathrm{~mm}$ sebagai unit proteksi radiasi dan dilengkapi dengan sistem pendingin ruangan ber-AC.

Keadaan ini menunjukkan bahwa beberapa komponen radiografi konvensional tersebut membentuk system Radiografi Konvensional (RK) mobile yang fungsional [7]. Unit mesin sinar-X ditunjukkan pada Gambar 4. 


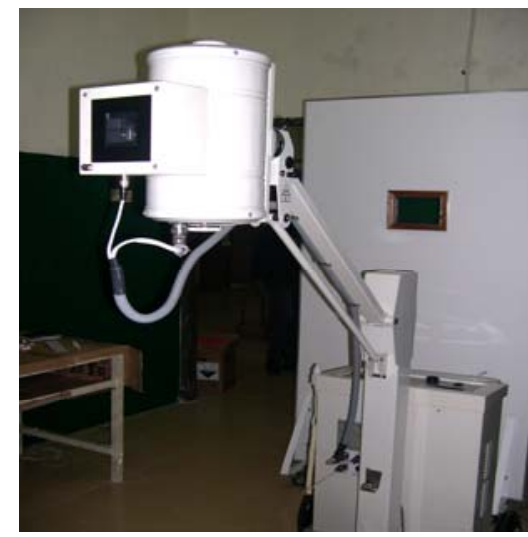

Gambar 4. Unit sistem RK di lab Fisika Medik UNNES.

\section{B. Eksperimental}

Secara skematis, rancang bangun sistem Radiografi Digital berbasis kamera digital dilukiskan seperti Gambar 5. Skema teresebut menjelaskan tentang sistem Radiografi Konvensional yang dimodifikasi menjadi sistem Radiografi Digital berbasis intensifying screen dengan mode radiografi sebagai suatu unit pencitraan yang ada di RS Daerah atau Puskesmas. Experimen harus dilakukan pada ruang kedap cahaya, sehingga dengan setting kamera yang sesuai ciitra radiograf dapat ditangkap dengan baik. Dengan menempatkan intensifying screen dibelakang obyek dan menambah kaca timbal untuk melindungi terpaan sinar-X pada kamera, maka dihasilkan citra radiograf digital dengan resolusi tinggi.

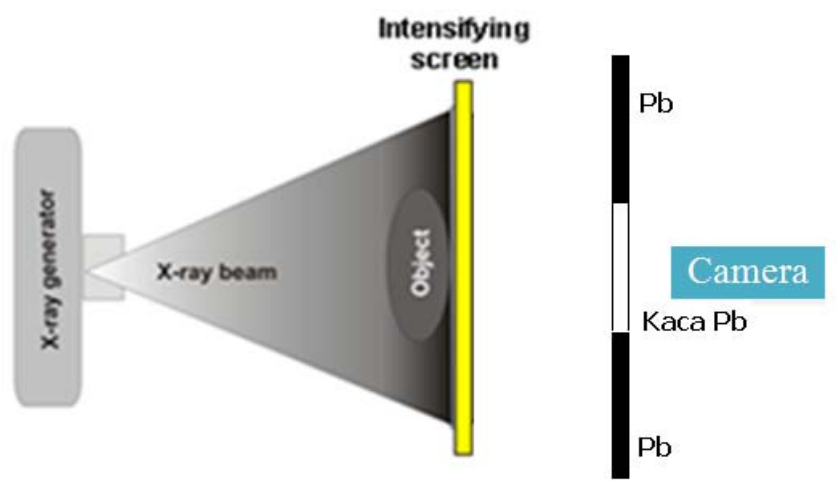

Gambar 5. Rancang bangun sistem RD berbasis kamera digital

Data radiograf digital yang diperoleh kemudian dibaca dengan PC melalui layar monitor. Dengan software pengolah citra yang telah dibangun sebelumnya maka citra dapat diolah dengan software tersebut, sehingga pemrosesan film seperti dalam radiografi konvensional tidak diperlukan lagi.

\section{HASIL DAN PEMBAHASAN}

Pada proses radiografi digital hampir sama dengan proses raiografi film, yaitu memerlukan waktu 0,25 - 0,50 detik untuk sekali peparan. Akan tetapi nilai tegangan dan arus operasional tabung sinar-x untuk menghasilkan intensitas sinar-x yang sama relatif lebih kecil dengan faktor eksposi adalah tegangan anode-katode $60 \mathrm{kV}$, arus filamen $16 \mathrm{~mA}$ dan waktu 0,5 s. Bandingkan dengan faktor eksposi untuk radiografi film, tegangan anode-katode $80-125 \mathrm{kV}$ dan arus filamen $50 \mathrm{~mA}-200 \mathrm{~mA}$.

Gambar 6 menunjukkan hasil pencitraan radiografi sinar$\mathrm{X}$ berbasis kamera digital pada obyek sepwedge yang dioperasikan pada mode radiografi dengan setting warna pada kamera adalah true color. Faktor eksposi yang digunakan pada mesin sinat-X adalah: $60 \mathrm{kV}, 0,5 \mathrm{~s}$ dan 63 $\mathrm{mA}$. Hasil yang diperoeh adalah radiograf dengan warna kehijauan, resolusi dan detailnya masih kurang (Gambar 5). Warna kehijauan ini tak sesuai dengan warna keluaran radiograf sistem CR, sehingga perlu setting kamera disesuaikan dengan mengubah setting warna true color menjadi grey. Dari 7 step stepwedge bisa dibuat radiograf tersebut, bisa diperoleh 5 step radiograf layak baca, ini menunjukkan bahwa sistem RD yang dibangun mempnyai kontras cukup baik.

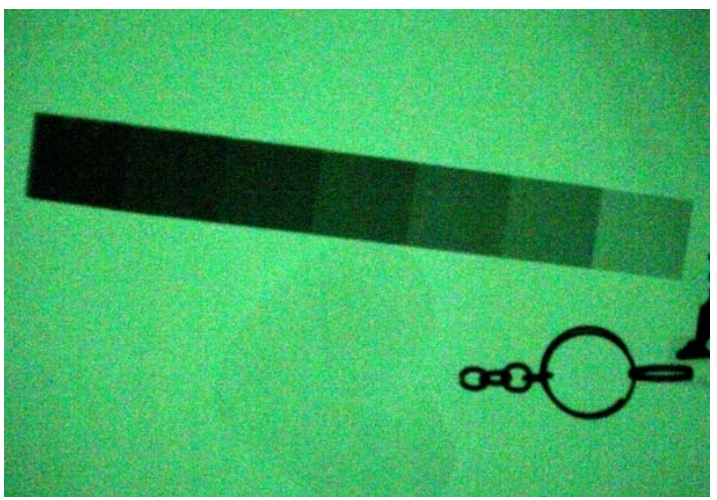

Gambar 6. Radiograf stepwedge, setting warna true color

Dengan menggunakan setting kamera berupa warna grey, shutter 0,5 s, dan ISO 6400 diperoleh radiograf digital tangan volunteer sama atau serupa dengan keluaran radiograf sistem CR, seperti yang ditunjukkan pada Gambar 7. Jenis file tersbut adalah JPEG, sedang ukuran file foto adalah 5184 x3456 pixels.

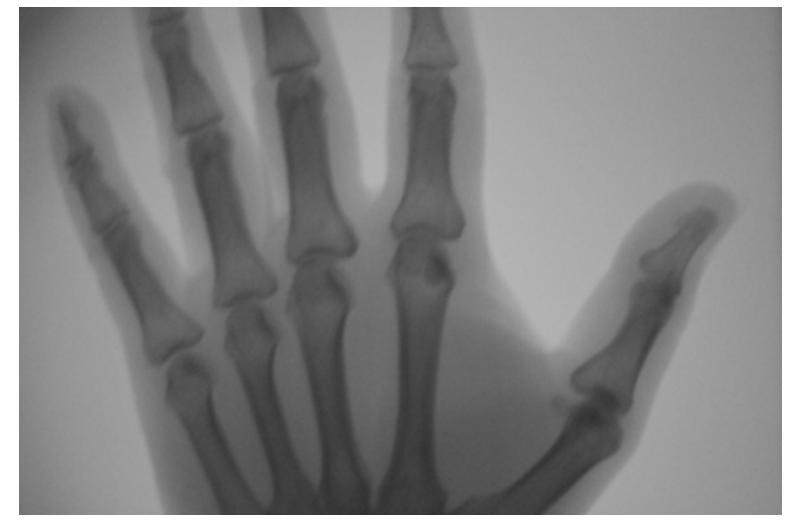

Gambar 7. Citra Radiograf tangan volunteer, format JPEG 
Berbeda dengan file radiograf digital pada keluaran radiograf tangan sistem RD pada riset sebelumnya, yaitu dengan dimensi 720 x 480 pixels [7], seperti diunjukkan pada Gamba 8. Dan bandingkan keluaran radiograf tangan sistem RD berbasis kamera digital dengan dimensi 5184x3456 pixels (Gambar 9). Sepintas terlihat bahwa Gambar 7 dan 8 kelihatannya tidak nampak ada perbedaan, namun jika gambar dibesarkan maka Gambar 7 mudah kabur atau pecah, berbeda dengan Ganbar 8, masih tetap baik karena resolusinya lebih besar.

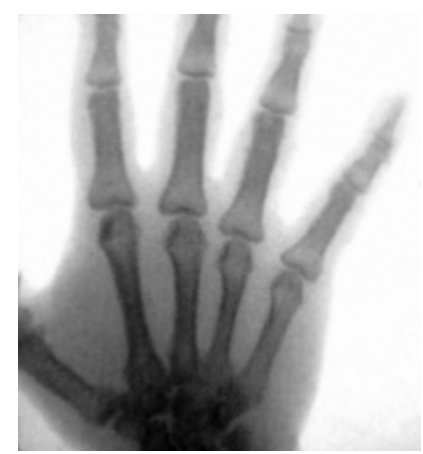

Gambar 8. Radiograf tangan, dimensi 720x480

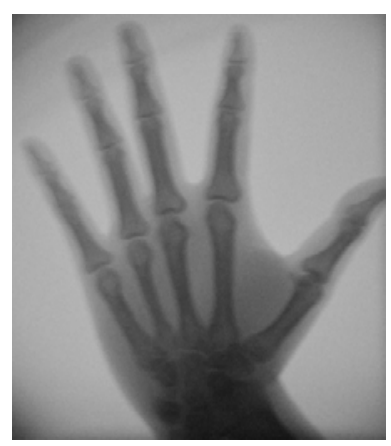

Gambar 9. Radiograf tangan, dimensi 5184x3456
Untuk jelasnya pada Tabel 1 ditunjukkan perbandingan antara studi sistem RD pada tahun 2010, sistem CR pada studi disertasi dan studi sistem RD pada tahun 2012.

Tabel 1. Perbandingan dimensi dan ukuran file radiograf untuk RD 2010, CR Kodak di RSDK dan RD 2012

\begin{tabular}{llll}
\hline \multicolumn{1}{c}{ Studi } & \multicolumn{1}{c}{2010} & \multicolumn{1}{c}{ CR } & \multicolumn{1}{c}{2012} \\
\hline Dimension & $720 \times 480$ & 2048x2500 & 5184x3456 \\
Size & 0,98 MB & $9,76 \mathrm{MB}$ & 5,30 MB \\
Type & Bitmap imag & Bitmap image & JPEG Image \\
Camera & CCD & Image plate & DSLR \\
Biaya & Murah & Sangat mahal & Terjangkau \\
\hline
\end{tabular}

Pada Tabel 1, untuk ketiga studi yang telah dilakukan, yaitu penelitian Hibah Strategi [2], sistem CR pada disertasi [7] dan Dipa Unnes [8] dapat ditunjukkan bahwa dari studi tersebut, studi menggunakan kamera DSLR paling memungkinkan untuk digunakan sebagai pengganti sistem CR yang sangat mahal.

\section{KESIMPULAN}

Melalui kajian ini dapat ditunjukkan bahwa proses digitisasi citra radiografi menggunakan intensifying screen berbasis kamera digital dapat menghemat tenaga listrik, mereduksi dosis radiasi yang diterima pasien, mereduksi waktu paparan dan dapat menghasilkan citra tulang tangan dengan resolusi lebih tinggi.
Berdasarkan kajian ini pula diperoleh pemahaman bahwa proses digitisasi dapat dilakukan dengan komponen yang sederhana, yang tersedia dan mudah diperoleh di pasar domestik. Hasil penelitian ini dapat digunakan sebagai landasan rekomendasi untuk meningkatkan kinerja fasilitas radiografi menggunakan instensifying screen berasis kamera digital yang terdapat di berbagai RS Daerah atau Puskesmas di Indonesia sebelum mempertimbangkan untuk melakukan investasi berupa pengadaan sistem CR yang mahal.

\section{UCAPAN TERIMA KASIH}

Penulis mengucapkan terima kasih kepada Kalab Fisika Unnes yang telah memberi banyak fasilitas dalam kegiatan studi ini. Juga terima kasih saya sampaikan kepada Mutaqien, SSi, Wasi Sakti< SPd atas bantuannya dalam studi ini.

\section{PUSTAKA}

[1] Linuma, G., Ushio, K., Ishikawa, T., Nawano, S., Sekiguchi, R., Satake, M. Diagnostic of Gastric Cancers: Comparison of Conventional Radiography and Digital Radiography with a 4 Million-Pixel Chargecoupled Device. RSNA Radiology. 2000, 214;497-502.

[2] Susilo, Sunarno, Azam, M. dan Anam, C. Rancangbangun sistem pencitraan radiografi digital untuk pengembangan layanan Rumah Sakit Daerah dalam pelaksanaan otonomi daerah dan desentralisasi. Laporan penelitian Penelitian Unggulan Strategis Nasional, tidak diterbitkan - Dikti, Jakarta, 2010.

[3]. Fasbender R, Schaetzing R. New computed radiography technologies in digital radiography. Radiologe 2003;43(5):367-73.

[4]. Chandrakant, M.S., Barthur, A., Kambadakone, A., Narayanan, N., Rajagopal K. V. 2011. Computed Radiography Image Artifacts Revisited. AJR. 196:W37W47. doi:10.2214.

[5]. Lanca L, Silva A. Digital radiography detectors - A technical overview: Part 1. Radiography 2009;15:58-62.

[6] Anonymous, 2012. Daftar Barang/Peralatan Pengadaan Peralatan Laboratorium MIPA, FBS, PTIK Universitas Negeri Semarang. PT Caturindo Karsa Manunggal Utama.

[7] Anonymous. 2009. The mobile diagnostic X-ray machine - The user manual, Type SF100 BY, Shanghai Guang Zheng medical instrument limited company.

[7]. Susilo, Pencitraan tulang dengan perangkat lunak berbasis Matlab pada radiografi digiral untuk diagnosis metastasis tulang, disertasi, Program Doktor Ilmu Kedokteran Undip, Semarang, 2012. 